\title{
Challenges facing colloidal delivery systems: From synthesis to the clinic
}

\author{
Angus P. R. Johnston, Georgina K. Such, Sher Leen Ng, Frank Caruso* \\ Centre for Nanoscience and Nanotechnology, Department of Chemical and \\ Biomolecular Engineering, The University of Melbourne, Victoria 3010, Australia \\ *Corresponding author. Tel: +61 38344 3461; fax +61 38344 4153. E-mail: \\ fcaruso@unimelb.edu.au
}

\begin{abstract}
Improving therapeutic delivery to the body will have significant benefits for the treatment of a variety of diseases. Incorporating drugs inside engineered colloidal carriers is a promising approach that can lead to improved drug delivery. Such carriers offer a number of advantages, as they can protect therapeutic cargo from degradation by the body, limit potentially harmful side effects of the drug, and also allow targeted drug delivery to the desired site of action. Colloidal carriers have the potential to enable clinical use of a number of therapeutics, such as siRNA and peptides, which if administered in their naked form degrade before demonstrating a viable therapeutic effect. A number of challenges, such as efficient therapeutic loading into the carrier, targeted and specific delivery in the body whilst evading biological defence mechanisms, and controlled release of therapeutically active cargo, must be met for these systems to be clinically relevant. In this review, we focus on recent advances and some of the pertinent challenges faced in developing clinically relevant colloidal drug carriers. We primarily focus on self-assembled carriers such as liposomes, polymer micelles and polymersomes, and carriers prepared through templated assembly, for example, layer-by-layer assembled capsules and PRINT (particle replication in non-wetting templates) particles.
\end{abstract}

Keywords: Drug Delivery, Liposomes, Micelles, Polymersomes, Layer-by-Layer, Targeting, Biodistribution.

\section{Introduction}

Recent advances in the assembly of responsive, nanoengineered colloidal carriers have shown potential for improving drug delivery for a range of diseases [1-3]. Current treatments for diseases such as cancer are limited by the harmful side effects of chemotherapy drugs before they reach the site of action. Developments in vaccine and gene therapy are also challenging due to degradation of sensitive cargo such as DNA, RNA or peptides. Thus, the incorporation of drugs into nanoengineered carriers has the potential to dramatically improve treatment options by protecting the cargo from degradation in vivo, limiting any potential harmful side effects and targeting the therapeutic directly to the site of action.

However, certain critical challenges must be met when developing drug delivery systems, including: efficient therapeutic loading into the carrier; targeted and specific delivery in the body whilst evading biological defence mechanisms; and controlled 
release of therapeutically active cargo. The development of a range of self-assembled delivery systems offers the potential to achieve all of these goals by careful design of the molecular building blocks. In this review, we highlight some of the recent developments in the assembly of nanoengineered colloidal drug carriers, drug loading and release from these carriers, and their application in vitro and in vivo. We focus on colloidal carriers that have shown promise in clinical studies (e.g., liposomes, polymer micelles and polymer particles), and emerging carriers such as polymersomes and those prepared from templated-assembly (LbL capsules and PRINT particles). We also present some systems that are larger than the colloidal size regime, however, the techniques used in their assembly can readily afford submicronsized delivery systems. Hence, these systems can provide important insights that may be exploited and applied in the preparation of carriers in the colloidal domain.

\section{Particle Assembly/Formation}

A variety of self-assembly techniques have been employed to synthesise particles of different size, shape, composition and degradability. In this review, we focus on selfassembled systems that rely on either the spontaneous ordering of molecules into engineered structures (polymer complexes, liposomes, micelles, polymersomes) or the templated-assembly of layer-by-layer (LbL) capsules and PRINT (particle replication in non-wetting templates) nanoparticles (Figure 1). Other colloidal carriers, such as metal/inorganic nanoparticles [4], and biological mimics, such as virus particles [5], have also found application in therapeutic delivery and have been the subject of excellent recent reviews; hence, these systems will not be discussed further in this review.

\subsection{Liposomes}

An attractive option for the design of delivery systems is to mimic structures already present in vivo. Thus, a great deal of research has focused on the design of liposomebased systems [6]. The structure of a liposome consists of a microscopic vesicle assembled from a lipid bilayer, with an aqueous interior and a hydrophobic membrane. Lipids are readily degradable in vivo, allowing the components of the delivery system to be removed easily from the body. In addition, the presence of a hydrophobic and hydrophilic domain within the structure allows flexibility in loading a variety of therapeutic cargos [7]. Liposomes are commonly synthesised using a number of approaches, including thin-film hydration, solvent injection or reversephase evaporation techniques. To engineer the vesicles to smaller or more uniform sizes both sonication and extrusion can be used. Liposomes have been one of the most successful delivery systems so far, with a number of therapies clinically available for treatment of cancer, including doxorubicin (Doxil ${ }^{\circledR}$ ) and daunorubicin (DaunoXome ${ }^{\circledR}$ ) [6]. However, there are still challenges with liposomes that need to be addressed, such as long-term stability in vivo [7]. Modification of the surface of liposomes with poly(ethylene glycol) (PEG) is one approach to improve both the stability and blood circulation time [8,9]. Moreover, the use of natural building blocks such as lipids makes it challenging to engineer the triggered release of cargo under specific conditions. This challenge has been addressed by incorporating $\mathrm{pH}-$ and light-responsive elements into the lipid bilayer (see Section 3.1) [10]. Furthermore, the loading of liposomes is typically non-covalent and therefore cargo leakage can be 
an issue, especially in the case of hydrophobic drugs when the liposome is in contact with plasma proteins or cell membranes [10].

\subsection{Polymer Micelles and Polymersomes}

In the last decade there has been significant research in the field of self-assembled polymer architectures [11]. Polymers can self-assemble into a variety of different structures, with two of the most commonly employed being micelles and polymersomes. Polymer micelles are generally nanometre-sized spheres, 20-100 nm in size, with a hydrophobic solid core and a hydrophilic exterior, and are significantly more stable than their surfactant-based counterparts [11]. These structures spontaneously form above the critical micelle concentration (CMC) of the polymers. Other shapes such as worm-like micelles can also be engineered and these structures have shown significant promise for prolonging circulation times in vivo [12,13]. In contrast to micelles, polymersomes have a hollow vesicle structure, similar to liposomes, with a hydrophobic membrane, hydrophilic surface and an aqueous interior [14]. As with liposomes, thin-film hydration, solvent injection or reversephase evaporation techniques are employed to form the polymersome structure. Sonication, extrusion and size exclusion chromatography (SEC) can be used to lower the polydispersity of the dispersions. While there are a range of polymer structures that can be used to assemble micelles and polymersomes, they are typically formed from amphiphilic block copolymers. Many factors influence the architecture of the nanostructure formed, including the chemical structure, the copolymer concentration in solution, and the solvent properties. A particularly significant factor is the volume ratio of the hydrophilic to hydrophobic block [15]. As a general rule, copolymers with hydrophilic to hydrophobic ratios greater than 1:1 form micelles, copolymers with ratios less than 1:2 favour vesicles and those with ratios less than 1:3 may form a range of structures such as vesicles, inverted microstructures or macroscopic precipitates.

Both micelles and polymersomes have been successfully loaded with a range of therapeutics and active components [16]. Micelles are somewhat more limited for loading, as they only contain a hydrophobic interior, thus making them suited for loading hydrophobic cargo. In contrast, polymersomes have a similar structure to liposomes, making them capable of loading both hydrophobic and hydrophilic drugs [17]. They also have a number of advantages over their lipid counterparts. For example, they are more stable and robust to a range of conditions [18]. Also, as the copolymers that form the structure are synthetic, they can be readily modified to tune their fluidity and permeability [18-20]. Furthermore, the surface of the polymersomes can be modified with a diverse array of molecules to tune their interactions with the environment [21].

\subsection{Polymer Particles}

While a significant amount of research has been focused on designing highly ordered self-assembled structures, bulk processes for particle synthesis are also of interest, as they offer the advantage of easier scale-up for commercial application. Polymer nanoparticles are commonly designed from polymers that can be readily degraded in vivo. These include poly(lactic acid) (PLA), poly(glycolic acid) (PGA) or poly(lacticco-glycolic acid) (PLGA), which degrade to form natural by-products of cellular metabolism [22]. Polymer nanoparticles can be synthesised through the 
polymerisation of monomers (emulsion or dispersion polymerisation) or by dispersion of polymers (nanoprecipitation or solvent evaporation) [23]. Loading these particles is generally achieved by incorporating the cargo during the synthesis process. One clinical example of these particles is Abraxane ${ }^{\circledR}$, which consists of paclitaxel bound to $\sim 130 \mathrm{~nm}$ albumin particles. Release is observed once the nanoparticles begin to degrade in vivo through a combination of desorption, diffusion and erosion processes. In general, such materials face a number of challenges, including synthesising a monodisperse population of nanoparticles and the non-targeted leakage of therapeutic cargo [24].

Another relatively straightforward synthetic approach is based on complexation of polyions to form polyion complexes (PIC) and PIC micelles (PICM) [10]. PICs are formed by electrostatic interactions between a cationic polymer, such as poly(ethylene imine) (PEI), and anionic nucleic acids. Such materials are highly charged and often have limited circulation times [10]. Therefore, a second generation of these materials, PICMs, have been developed where the charged component is shielded using stealth materials such as PEG [25]. A variety of PICM systems have successfully demonstrated siRNA and plasmid delivery in vivo. These systems can also be readily combined with targeting and responsive stabilisation to optimise therapeutic outcomes $[26,27]$. A related system has recently demonstrated potential in human clinical trials with successful siRNA delivery in vivo using a cyclodextrin-based polyion with PEG stabilisation [28].

The size of spontaneously self-assembled systems is to a large extent governed by the intrinsic properties of the assembling molecules. Thus there are limitations to controlling the size of the particles formed. Sonication and extrusion can be used to narrow the polydispersity of liposome, micelle and polymersome systems, and size exclusion chromatography can be used to fractionate the preparations. An alternative approach to assemble carriers with high control over their size is via templated assembly.

\subsection{LbL Capsules}

The LbL approach relies on the alternate deposition of materials through complementary interactions [29]. Although originally introduced for electrostatic interactions to drive film assembly, recent studies have used a range of interactions, including hydrogen-bonding and sequential covalent reactions [30]. The LbL technique has generated significant interest, as it is simple, versatile and allows precise engineering of films constructed by the choice of materials or the conditions used. When sacrificial particle templates are used as substrates for multilayer assembly [31], the particles can be readily removed to form polymer capsules of defined size, composition and functionality. The wall thickness of the capsules can also be controlled with nanoscale resolution, with each layer typically only several nanometres thick. Thus, the ultra-thin walls confer flexibility to the capsules, a property that is expected to enhance blood circulation and tumour accessibility of the capsules (see Sections 4 and 5). For biological applications, it is critical that the polymers used are biocompatible. Carriers based on N-(2hydroxypropyl)methacrylamide (HPMA) [32], poly-l-arginine)/dextran sulfate [33], and poly(methacrylic acid) (PMA)/poly(vinylpyrrolidone) (PVPON) [33,34] have demonstrated significant potential both in vitro and in vivo. The PMA/PVPON 
hydrogen bonding pair is inherently unstable at physiological conditions; however, it can be stabilised by using either thiol-modified PMA (PMA ${ }_{\mathrm{SH}}$ ) [34], which is crosslinked by the formation of disulfide bridges, or by cross-linking alkyne modified PVPON with a bifunctional azide linker [35]. The latter approach enables a variety of biologically cleavable linkers to be incorporated into the capsules.

LbL materials are based on a multilayer structure so there is potential to create stratified materials with different characteristics, including loading more than one cargo or combinations of therapeutic and imaging agents. LbL capsules have been formed from diverse templates, including spherical particles ranging in size from about $20 \mathrm{~nm}$ to $>10 \mu \mathrm{m}$, high-aspect-ratio nanorods, porous membranes, and cells [36]. Currently, there is a significant drive towards making sub-500 nm sized colloidally stable LbL capsules.

\subsection{Lithographic Templates}

Another approach for designing particle delivery systems is the PRINT process [37]. This process is a top-down lithographic fabrication technique for the synthesis of nano- and microparticles. One significant advantage of this approach is that the lithographic template can be adapted to synthesise a range of particles of different sizes and shapes. This allows the influence of specific parameters such as size to be determined in vivo because other variables such as particle composition can be kept constant. Details on the preparation and potential uses of PRINT particles can be found in recent reviews [38, 39].

\section{Loading and Release Mechanisms}

For a delivery system to have therapeutic relevance, it is fundamental that the material allows effective loading and release of cargo, such as anticancer drugs, DNA or proteins. Many of the therapeutics investigated for loading within delivery systems are either toxic to healthy cells or extremely fragile. Therefore, the delivery system should ideally release only at specific targeted sites to optimise the therapeutic outcomes for the patient. The controlled loading and release in many colloidal delivery systems is still a significant and ongoing challenge.

\subsection{Liposomes}

Loading of liposomes is typically based on non-covalent interactions of the cargo with either the hydrophilic aqueous interior or the hydrophobic membrane [10]. This approach has been used to produce liposomal formulations, including Doxil ${ }^{\circledR}$ and Caelyx ${ }^{\circledR}$, which have progressed to clinical application [6]. Doxil ${ }^{\circledR}$ is based on a PEG-modified liposome system loaded with DOX, where DOX is loaded by inducing an ammonium sulfate gradient for drug loading. The DOX is trapped inside the interior as a salt precipitate, thus it lacks osmotic effects and does not disrupt the stability of the vesicles. The DOX-loaded liposomes contain a stealth PEG outer layer that increases the stability of the liposomes while also increasing the blood circulation time. However, some leakage of the cargo does occur. It is thought that cargo release is achieved in the interstitial fluid of tumours by the disruption of the lipid bilayers by phospholipase [40]. 
Protein and peptides are of particular interest for delivery applications. Due to their specific mode of action they can be delivered in relatively small doses; however their application is restricted by a number of factors, including short half-life in vivo if unprotected. To address these challenges there has been a significant amount of work on the use of carriers to load peptide cargo. In one such study an inhalable liposomal formulation loaded with a vasoactive intestinal peptide (VIP) was prepared. The formulation was investigated for a response on rat arteries and showed greater vasorelaxation than the free peptide [41].

One promising technique to enable greater control over liposomal release is doping liposomes with $\mathrm{pH}$-responsive lipids, such as phosphatidylethanolamines (e.g., dioleoylphosphatylethanolamine, DOPE) [42]. This class of lipid is readily incorporated into the liposomal structure; however, upon entry into an acidic compartment, the DOPE changes from a lamellar to a hexagonal phase, leading to fusion with the endosomal membrane. Depending on the lipid composition within these liposomes, they can be leaky and subject to interchange with serum proteins in the body. PEG can be added to these formulations to improve stability, and while this reduces the $\mathrm{pH}$-responsive effect, the PEG can also contribute to fusogenic capabilities [42]. In another approach, zwitterionic lipids based on glutamic acid were synthesised and used to assemble pH-responsive liposomes [35]. These liposomes were negatively charged at physiological $\mathrm{pH}$ but became cationic in the acidic environment of the endosome, allowing the materials to fuse with the membrane and release their cargo (DOX) in the cytoplasm. In vivo studies demonstrated improved tumour shrinking in a mouse of these zwitterionic liposomes compared to free DOX and non-pH-responsive liposomes [43].

\subsection{Polymer micelles}

The loading of micelles commonly relies on physical encapsulation during the assembly process, whereby hydrophobic drug molecules can be sequestered in the hydrophobic core [44]. In one example, paclitaxel (PTX) was loaded into a micellar carrier assembled from PEG- $b$-poly(aspartate) modified with 4-phenyl-1-butanolate [45]. In vivo studies showed that this micellar system exhibited higher plasma concentration compared to free PTX. This promising system is currently the subject of ongoing clinical trials.

One limitation with drug loading based on physical entrapment is that many drugs are small in size and can leak from carriers such as micelles. To address this, a variety of intermolecular interactions have been engineered into micellar structures to achieve better control over micelle stability, drug loading and release. In one interesting example, Kataoka and co-workers improved drug retention by sequestering DOX though $\pi-\pi$ interactions [46,47]. This system is also the focus of clinical trials [48]. Yoo and Park have also shown improved loading efficiency of DOX by chemically conjugating it to PLGA-PEG micelles [49]. Non-conjugated DOX exhibited burst-like release (within 3 days) compared to the sustained liberation of conjugated DOX over 2 weeks due to the slow hydrolysis of the PLGA. It has also been demonstrated that DOX attached via an acid-labile hydrazone linkage achieves higher anti-tumour activity in tumour-bearing mice compared to the free drug [50,51].

\subsection{Polymersomes}


Similar to liposomes, polymersomes have the capacity to load both hydrophobic and hydrophilic drugs in the membrane and interior, respectively. The synthetic polymer amphiphiles have a higher molecular weight than phospholipids, thus imparting thicker and more stable membranes as compared to liposomes, providing them with higher loading capacity and extended periods of cargo retention [52]. In a recent study, Discher and co-workers demonstrated the use of degradable PEG-PLA polymersomes to effectively load and release both hydrophobic and hydrophilic therapeutics [53]. A hydrophobic drug, TAX, was post-loaded into the vesicles while a hydrophilic drug, DOX, was incorporated into the polymersomes using a $\mathrm{pH}$ gradient. The hydrophobic drug-loading into the polymersome membranes was almost 10-fold more efficient than liposomal loading, possibly due to the thicker membrane of the polymersomes. The majority of drug was released within 2 days when exposed to simulated endosomal conditions ( $\mathrm{pH} 5.5$ and $37{ }^{\circ} \mathrm{C}$ ) and demonstrated higher efficacy than free drug in vivo, preventing tumour growth (effect of TAX) in breast cancer cells and killing the cells (effect of DOX and TAX) [53].

Due to the synthetic nature of polymersomes, various release mechanisms can also be incorporated into the materials through response to external stimuli such as $\mathrm{pH}$, oxidative species and enzyme degradation. In one study by Lomas and co-workers, a $\mathrm{pH}$-responsive diblock copolymer, poly(2-(methacryloyloxy)ethylphosphorylcholine)-co-poly(2-(diisopropylamino)ethyl methacrylate) (PMPCPDPA), was used to form stable vesicles [54]. The PDPA has a $\mathrm{pK}_{\mathrm{a}}$ of $\sim 6.5$, therefore at physiological $\mathrm{pH}$ it is hydrophobic and forms the hydrophobic domain within the polymersome structure. However, in a mildly acidic environment, the tertiary amine groups on the PDPA chains protonate, and the polymer switches from hydrophobic to hydrophilic. This transition causes the polymersome structure to disassemble at around $\mathrm{pH}$ 5-6 to form molecularly soluble copolymer chains (Figure 2) [55]. Plasmid DNA was encapsulated into the polymer vesicles by first dissolving PMPC-PDPA copolymer chains in mildly acidic aqueous solution with plasmid DNA. At this $\mathrm{pH}$ the polymer was cationic, so it readily interacted with the negatively charged DNA. The $\mathrm{pH}$ was then increased to form the vesicle structure, trapping the DNA in the interior. When these polymersomes are internalised into the acidic compartments of cells, the reduction in $\mathrm{pH}$ triggered disassembly of the polymersomes. The released plasmid DNA maintained its integrity, as shown by green fluorescent protein (GFP) expression in cells.

\subsection{Polymer Particles}

Polymer nanoparticles can achieve controlled drug release by exploiting different surface or bulk erosion rates through a choice of biodegradable polymers and external triggers such as $\mathrm{pH}$ and temperature changes. One of the most widely used systems, PLGA, has readily tuneable degradation based on the lactic to glycolic acid ratio (ranging from days to months). However, there are several challenges with these materials, including DNA instability when loaded into these systems, as well as poor loading and transfection efficiency [24]. These materials also commonly display an initial burst release of therapeutic cargo, which has a tendency to occur nonspecifically. One approach that has been investigated to improve properties such as loading and transfection efficiency is the incorporation of cationic components, such as poly( $\beta$-amino esters) (PBAE). Langer and co-workers demonstrated that PLGA particles incorporating 15\% and 25\% PBAE showed enhanced transfection efficiency. 
However, the incorporation of these polymers led to higher charge and some toxicity issues [56]. An alternative system, based on acetal-modified dextran microparticles, showed the degradation rate of particles could be tuned by controlling the polymer composition [57]. In this work, model DNA sequences were incorporated into the particles with a minor component of PBAE. In vitro results revealed good cargo retention at $\mathrm{pH} 7.4$, while it was released effectively at $\mathrm{pH} 5$. Unlike many gene therapy systems, these materials have low inherent charge, but still successfully transfect a number of cell lines.

A different approach to the synthesis of nanoparticles was recently demonstrated by Yan et al. [58]. In this approach, covalently modified proteins with either $\mathrm{pH}$ degradable or non-degradable polymer shells were formed. In both cases, the protein remained active in vitro; however, for proteins that underwent reactions with large substrates, such as other proteins, a degradable shell is more effective to enable the substrate to access the protein.

The loading mechanism of PICMs is based on the interaction of negatively charged DNA or siRNA with a cationic polymer. A range of PEG-polycation complexes have been investigated, including PEG-poly(L-lysine) copolymers [59] and more recently thiol-modified PEG-PLL block copolymers $[60,61]$, which allow the structure to be stabilised by disulfide bond formation. The additional thiol cross-linking provided the micelles with enhanced stability during blood circulation, while releasing plasmid DNA and siRNA inside the target cells through cleavage of the disulfide bonds under the reducing environment of the cytoplasm. Using a similar loading technique, a polyion nanoparticle has recently been used for the first siRNA delivery within humans [28]. A positively charged cyclodextrin was complexed with siRNA and the resulting nanoparticles were stabilised with an adamantane-modified PEG for improved biodistribution [62].

Loading of PRINT particles with cargo such as proteins, small molecule drugs and siRNA has been achieved by loading an aqueous solution of the cargo into a preformed mould and sealing it with another polymer film with higher surface energy using a roller and increased pressure [63].

\subsection{LbL Capsules}

In LbL assembly, various approaches to cargo loading have been explored, including pre- or post-loading the capsule interior and incorporating cargo into the capsule walls [64-66]. Pre-loading cargo can be achieved by immobilising a therapeutic compound onto template particles, followed by the assembly of polymeric layers and removal of the core particles. The degradation behaviour of these capsules can be tuned by incorporating responsive components into the films. Using this technique capsules have been prepared that are responsive to, for example,: infrared light, by incorporating gold nanoparticles [67]; temperature, by incorporating polymers which undergo an LCST transition [68]; enzymatic degradation, by incorporating biodegradable polymers such as polypeptides [33] and nucleic acids [69]; pH, by using weak polyelectrolytes [70]; and redox potential, by using disulfide-stabilised systems [34,35].

Recently, Sexton et al. investigated the in vivo processing of $500 \mathrm{~nm} \mathrm{PMA}_{\mathrm{SH}}$ capsules loaded with whole ovalbumin (OVA) and short OVA epitopes [71]. 
Presentation via both the MHC Class I and Class II pathways were observed, with a significantly stronger Class II response. For effective viral vaccines, an increased Class I response would be desirable, which requires control over the intracellular fate (see Section 6). Similar results have been observed with larger poly(arginine)/dextran sulfate capsules with encapsulated OVA [72].

Anticancer drugs such as DOX have also been encapsulated within LbL films. The highly permeable nature of the films means that low molecular weight drugs are challenging to encapsulate, so to address this, DOX has been covalently linked to polymers. Decher and co-workers used a cleavable peptide linker to attach DOX to HPMA that was assembled onto gold nanoparticles [32]. When a linker susceptible to cleavage by cathepsin (a lysosomal enzyme) was used, release of DOX occurred over 24 h. No significant release was observed from particles that did not contain the cathepsin peptide. In a similar approach, Ochs et al. functionalised PLGA with DOX and drug release was observed in the presence of proteases [73]. It was also demonstrated that these capsules efficiently killed cancer cells. In an alternative approach, PMA ${ }_{S H}$ capsules were post-loaded with an oil phase containing DOX [74]. This system showed cell cytotoxicity three orders of magnitude greater than free DOX and a distinctly different cellular distribution of the drug [75]. A comprehensive recent review on the use of LbL capsules for therapeutic delivery can be found elsewhere [76].

\section{Biodistribution}

One of the major challenges faced by drug carriers is the rapid clearance by the natural defence mechanisms of the body. Clearance by white blood cells, the mononuclear phagocytic system (MPS) (also known as the reticuloendothelial system, RES), and the renal system play a major role in the efficacy of colloidal delivery systems [77]. Typically, colloidal drug carriers are administered to the body through intravenous injection to achieve quick distribution of the particles throughout the body via the circulatory system, although specialised treatments can use subcutaneous (below the skin) and interperitoneal (body cavity) injections. When a foreign material is administered into the bloodstream, plasma proteins, such as opsonins, immediately adhere to the surface, enabling recognition by immune cells [77]. Phagocytic white blood cells are the first line of defence for the removal of foreign materials from the blood. They have evolved as the natural defence against bacterial or fungal infections through phagocytosis (eating) of the foreign material, and are well adapted to phagocytosing particles in the sub-micrometre and micrometre size range. Tissue resident macrophages are more fully differentiated phagocytes that reside in the liver (Kupffer cells) and spleen (sinusoidal lining cells) as part of the MPS [77]. They also play a key role in the elimination of particulate materials. Renal filtration by the kidney is the third major clearance path, although as it is responsible for excreting small material below $6 \mathrm{~nm}$ [78], renal clearance is not a major issue for the systems discussed in this review. This clearance mechanism does, however, play an important role in the elimination of degraded components of the colloidal carriers.

The foreign body response to particles is the result of a complex interplay of factors attributed to their size, composition, shape and surface properties. However, the key factors that govern particle clearance are limiting binding of plasma proteins and to 
ensure the size and flexibility of the particles are optimal to avoid accumulation in the liver and spleen.

\subsection{Size}

Spleenic sinusoids and Kupffer cell fenestration in the liver vary from 150 to $200 \mathrm{~nm}$ in diameter and are the primary filtering mechanism of the MPS [79]. These structures can effectively trap particles larger than this size, although flexible structures, like red blood cells (RBCs), can readily pass through the openings. In a fundamental study on the effect of particle size, Liu et al. investigated the biodistribution of phosphatidylcholine liposomes ranging in size from $\sim 40-450 \mathrm{~nm}$ in mice. After $4 \mathrm{~h}$, significant accumulation was observed in the liver for all sizes of liposomes, and liposomes larger than $100 \mathrm{~nm}$ showed increasing accumulation in the spleen. Correspondingly, the concentration of liposomes circulating in blood decreased exponentially with size. Interestingly, ganglioside liposomes, whilst still showing accumulation in the liver and spleen, exhibited optimal blood circulation at around $150 \mathrm{~nm}$ [80].

In another study, Fang et al. studied the effects of particle size on serum protein binding [81]. It was observed that PEG-functionalised nanoparticles less than $100 \mathrm{~nm}$ in size bound less than $6 \%$ of the total serum proteins, while $250 \mathrm{~nm}$ particles bound more than 34\%. It was suggested that the smaller particle size offered higher surface PEG chain density, which provided stealth properties for prolonging biodistribution (translating to decreased serum protein adsorption and phagocytic uptake, as well as extended circulation time in blood). Correspondingly, the macrophage uptake and blood clearance was higher for the larger particles.

\subsection{Shape and Flexibility}

Phagocytosis by macrophages is a major clearance mechanism for colloidal carriers and it has been recently shown that shape plays a role in particle recognition by macrophages [82]. By stretching polystyrene particles, Mitragotri and co-workers showed that particles with a longest dimension of 2-3 $\mu \mathrm{m}$ bound significantly more to macrophages than larger or smaller particles [83]. This corresponds directly to the size distribution of naturally occurring bacteria.

While it has been observed that spherical particles larger than $200 \mathrm{~nm}$ are effectively trapped in the liver and spleen, flexible and/or non-spherical particles have shown significantly longer circulation times. Discher and co-workers found that flexible worm-like micelles (filomicelles) were mostly dispersed in blood plasma ( 63\%) after $24 \mathrm{~h}$, rather than concentrating in specific organs or tissues [13,84]. The biodistribution and circulation times of these filomicelles showed significantly improved circulation times, over one week, as compared to spherical micelles of the same composition which were cleared within two days (Figure 3a).

To better understand the role shape plays in biodistribution, templated assembly (e.g., to form PRINT carriers [37]) offers a significant advantage, as it allows precise control over shape, such as the synthesis of spheres, cylinders, discs, and toroids. DeSimone and co-workers investigated the in vivo distribution of cylindrical PEGPRINT particles [85]. While the biodistribution of the cylinders was similar to conventional spherical nanoparticles, with sequestration mainly in the liver and 
spleen, this technique offers a tool to determine shape effects while controlling other variables such as composition and surface properties.

\subsection{Surface Properties}

Surface charge plays a key role in serum protein binding and the subsequent blood clearance of colloidal carriers. In general, charged particles display greater protein binding and clearance than uncharged particles [77]. A large proportion of serum and cell surface proteins are negatively charged and as such positively charged particles display high non-specific cellular binding and short blood circulation half-life. Although negatively charged particles exhibit lower serum protein binding, significant liver accumulation is still generally observed. Hydrophobic particles have been found to be opsonised more rapidly than hydrophilic particles due to the enhanced adsorption of blood serum proteins onto these surfaces [77].

In one study, Yamamoto et al. found that anionic spherical micelles could potentially evade the MPS of the liver and spleen more readily than neutral, functionalised counterparts [86]. However, other reports show that anionic molecules and particles suffer the tendency of accumulating preferentially in the liver compared to neutral analogues due to binding with serum proteins [87]. These variations suggest that other particle properties play a significant role in the biodistribution. In another study, Discher and co-workers investigated the biodistribution of polymersomes with a surface charge that mimics RBCs [88]. The results showed a trend of neutral polymersomes accumulating mostly in the liver and spleen, while anionic polymersomes were localised primarily in the liver with a relatively small amount in the spleen (Figure $3 \mathrm{a}, \mathrm{b})$.

PEG functionalisation is a well-established technique to mask the capsule surface and to limit non-specific protein binding [89]. PEG is a non-ionic, hydrophilic polymer and steric effects offered by adsorbed PEG play a significant role in the low-fouling nature of PEG-modified surfaces [77]. Studies have shown that the characteristics of the PEG layer, such as the thickness, overall surface charge, surface chain density (coverage), functional groups, and PEG conformation, all impact the way in which it interacts with opsonins and influences the particle biodistribution [77]. The use of PEG polymers with larger molecular weight (>2000 dalton) have consistently demonstrated prolonged blood circulation half-lives for particles in vivo [81,90]. This minimum molecular weight is needed to overcome the lack of flexibility of shorter PEG chains, which do not contribute substantially to reduce opsonisation. Photos et al. have demonstrated the direct correlation between polymersome blood circulation half-life with increasing PEG length and molecular weights [52]. However, very high molecular weights (>5000 dalton) can lead to protein entanglement. In addition, an optimal PEG surface coverage is required so that the chains have slightly restricted movements and confer sufficiently dense surface coverage, while not forming overly rigid layers, which exhibit reduced steric effects [77].

It is well documented that PEGylated liposomes exhibit less rapid clearance by the MPS and longer blood circulation times than their non-functionalised counterparts [91]. Some prominent commercial examples of PEGylated-liposomes loaded with DOX are Doxil ${ }^{\circledR}$ and Caelyx ${ }^{\circledR}[40]$, while other PEG-coated liposomal drug formulations which have progressed to clinical trials have also shown increased intratumour drug concentrations and better therapeutic responses than equivalent 
doses of non-PEGylated liposomes or free drug [92,93]. One advantage of the liposomal DOX formulation is the change in the biodistribution of the drug, particularly the reduced accumulation in the heart as compared to free drug. However, the liposomes do accumulate significantly in the skin, leading to different complications, such as severe skin burn and bleeding sores [91].

Other systems such as polymeric micelles and polymersomes have been prepared with PEG block copolymers and loaded with drugs in biological studies [52,94]. Free DOX (adriamycin) was rapidly cleared within $3 \mathrm{~h}$, as compared to polymeric micelles which demonstrated prolonged blood circulation of up to $24 \mathrm{~h}$, as well as increased accumulation in tumour tissue [95].

\section{Targeting}

To optimise the delivery of therapeutics to specific areas in the body, two distinct strategies have been employed: passive targeting, which exploits the Enhanced Permeability and Retention (EPR) effect of many tumours [96]; and active targeting, which relies on the binding of the particles to specific receptors on the surface of certain cells.

The EPR effect has been extensively used in a number of nanoparticle delivery systems to concentrate drugs within tumours. Particles naturally accumulate in tumours as the tumours have a high fluid flow and a large leaky vasculature. This is because tumour cells have high demand for oxygen and access to essential nutrients to support their rapid growth. The rapidly induced growth of the vesicles leads to poorly aligned epithelia cells and wide openings that enable the nanoparticles to become trapped [97]. The size of the tumour vasculature is highly dependent on the tumour type and age, with the upper size for effective particle retention ranging from $100 \mathrm{~nm}$ to $2 \mu \mathrm{m}$ [98]. A number of clinical trials have shown promising results based on the EPR effect [99]. One consideration with EPR targeting is that it is incompatible with combination therapies that rely on reducing the vasculature size and cutting off the nutrient supply to the tumour. The EPR effect has been shown to be highly promising, clinically relevant and relatively simple to enhance the delivery of drugs to tumours, however the effect is limited to the treatment of tumourous legions. For treating early stage cancer metastases, vaccines and other non-cancerous diseases, alternate targeting strategies are required.

More targeted localisation of particles can be achieved by functionalising the particle surface with molecules that bind to specific cells. This approach can be used to target diverse cells within the body, although a significant amount of work on this active targeting has largely focused on cancer therapy. Cancer cells are well known to overexpress certain proteins on their surface, such as folate, epithelial growth factor (EGF) and transferrin receptors. Folate receptors (FR) are also expressed on activated macrophages found in areas of inflammation and can therefore be a useful target to deliver drugs for rheumatoid arthritis and Crohn's disease [100]. Using PAAmodified liposomes, in vitro targeting showed more than a 10-fold increase in the binding of folate functionalised particles to KB cells compared to non-functionalised particles [101]. By comparison, cells deficient in the folate receptor showed less than a four-fold increase in particle uptake. Similar results have been observed with folic acid-functionalised PLGA particles [102]. In vivo experiments with PIC micelles 
have shown little change in the accumulation of folate particles in the tumours compared to the non-functionalised particles; however, tumours treated with folate particles showed slower growth than non-functionalised particles [103]. The increased therapeutic effect of the folate-functionalised particles is most probably due to the enhanced cellular uptake of the particles (see Section 6). One potential limitation with using receptors that are also expressed on healthy cells is that non-specific uptake of the drug is also observed. However, this technique still provides a significant therapeutic advantage over delivering the free drug.

Greater specificity can be achieved by employing antibodies that recognise antigens that are specifically expressed on the target cells. Examples of such antibody targets that have been coupled to particles include the huA33 antigen which is expressed on $>95 \%$ of colorectal cancer (CRC) and is only found on epithelial lining cells of the intestine [104], the HER2 receptor which is over-expressed on aggressive breast cancers [105], and the prostate membrane specific antigen (PMSA) [106]. Recently, LbL capsules assembled from PVPON that exhibit inherently low non-specific binding to cells were functionalised with a huA33 monoclonal antibody (mAb). It was demonstrated that efficient binding to CRC cells was possible even when the number of target cells was a very small percentage of the total cell population $(<0.1 \%)$ (Figure 4) [104]. Surgery is still the most efficient technique for removing large tumours and the primary role of chemotherapy is used to kill remaining cancer cells after the primary tumour has been removed. It is envisaged that the role of the next generation of colloidal drug carriers will be to seek out these metastatic (secondary) cancers, and as such the ability to minimise binding to healthy cells is critical.

\section{Cellular Internalisation and Fate}

The therapeutic effect of most drugs occurs in specific locations within the cell, so the intracellular fate of the drug is critical. Therefore, it is important to understand the mechanisms involved in internalisation of the delivery systems, as it plays a significant role in the intra-cellular trafficking and chemical environment that the therapeutic cargo is exposed to. Hydrophobic, low molecular weight compounds can passively diffuse across the lipid membrane, whilst certain other compounds can enter the cell via protein channels [107]. However, larger materials such as colloidal delivery systems enter via the energy-dependent internalisation pathway of endocytosis [107]. When internalised via this pathway, the particles are completely encapsulated within a lipid bilayer that isolates them from the rest of the cell (Figure 5).

Endocytosis is broadly categorised into two mechanisms: phagocytosis (cell eating) and pinocytosis (cell drinking) [108]. Phagocytosis is a solely particle driven process and is generally limited to specific cell types, such as macrophages and dendritic cells. Because phagocytosis of foreign material by macrophages is one of the first lines of defence for the immune system, it is an ongoing challenge to develop particles that evade macrophage clearance and maintain good biodistribution.

In contrast, pinocytosis occurs in almost all cell types and involves a number of distinct mechanisms, including: macropinocytosis, clathrin-mediated endocytosis, caveolae-mediated endocytosis and clathrin/caveolae independent pathways. 
Macropinocytosis is commonly associated with the uptake of large particles, as it can form endocytic vesicles up to $5 \mu \mathrm{m}$ in diameter [109]. The fate of the macropinosome enclosures (and the cargo) is highly dependent on the cell type, although in most cells acidification of the macropinosome occurs before it fuses with lysosomes [108]. Clathrin-mediated endocytosis (CME) is initiated by binding to cell surface receptors (such as transferrin or epidermal growth factor (EGF) receptors), which recruit a cytoplasmic protein (clathrin) to the cell membrane [107]. The clusters of clathrin form an invagination which engulfs the particle to form a 100-150 nm diameter clathrin-coated vesicle. As with the macropinocytotic pathway, these endosomes undergo rapid acidification. In caveolae-mediated endocytosis, caveosomes (literally little caves) form on the membrane mediated by small hydrophobic microdomains rich in cholesterol and glycosphingolipids [107]. Endosomes formed in this process are generally 50-60 nm and are distinct from endosomes formed from macropinocytosis and clathrin-mediated endocytosis, because they do not exhibit a drop in pH. Non-specific internalisation of colloidal carriers is essential for nontargeted delivery systems, as it enables entry of the drug into the cell. However, for targeted delivery systems, non-specific internalisation must be minimised to ensure internalisation occurs through a receptor-mediated process.

Engineering escape from endosomal compartments is fundamental for effective therapeutic delivery. The different endocytic mechanisms require various approaches to engineer escape from these compartments. For example, as the caveolae-mediated pathway does not lead to acidification of the endosome, $\mathrm{pH}$-induced release and escape is not an effective mechanism for this pathway. Similarly, the leaky nature of macropinosomes can enable endosomal escape more readily than the clathrinmediated pathway [108]. As cell type plays an important role in the internalisation of particles, it is not possible to give a definitive mechanism of internalisation for a specific particle type. However, certain particle characteristics such as size, surface charge, surface functionality and flexibility have a significant effect on the internalisation and subsequent fate of the particles.

In a fundamental investigation of polystyrene (PS) particles internalised by murine melanoma cells (B16-F10), Rejman et al. studied particles ranging in size from 50$1000 \mathrm{~nm}$ [110]. The smaller particles $<150 \mathrm{~nm}$ were rapidly internalised (less than 30 min) via a clathrin-mediated pathway. In contrast, larger particles $(>150 \mathrm{~nm})$ were only slowly internalised (2-3 h) and exhibited 8 to 10 -fold less internalisation than the smaller particles. Interestingly, $500 \mathrm{~nm}$ particle-internalisation appeared to be linked to the caveolae pathway. The role of caveolae in the internalisation of the particles was confirmed by the colocalisation of the particles with a protein that is critical to this mechanism (caveolin 1). This result is surprising as caveolae are generally thought to be in the 50-60 nm size range. As expected, particles internalised via the clathrin pathway localised with the lysosome, while the $500 \mathrm{~nm}$ particles did not associate with either the acidic late endosome or lysosome.

Surface charge also affects the internalisation of particles. Positively charged particles are typically internalised to a greater degree than negatively charged particles [111]. Studying the internalisation of PS in HeLa cells, it was observed that both macropinocytosis and clathrin play a role in the internalisation of positively charged $100 \mathrm{~nm}$ particles [112]. However, negatively charged PS particles were internalised via an undetermined clathrin/caveolae independent pathway. 
Surface functionalisation can also contribute to internalisation, particularly by incorporating surface groups that are found naturally on viruses. HIV-1 TAT is an arginine rich protein that helps the virus enter cells and avoid degradative lysosomal compartments [113]. To mimic this effect, liposomes have been functionalised with a high surface density of octaarginine (R8 - mimicking TAT) or the similarly charged octalysine (L8). Both functionalised liposomes were internalised (by NIH 3T3 cells) via a macropinocytic pathway [113]; however, similar particles with a low density of R8 were shown to be internalised via a clathrin-mediated pathway [114]. Liposomes functionalised with L8 localised with the lysosomes and exhibited very low transfection efficiency when delivering siRNA. However, high density R8 liposomes escaped from the early endosomal compartment and showed significantly higher transfection [113]. Interestingly, low density R8 liposomes did not escape the endosome and localised with the lysosome [114], suggesting that either a certain concentration of the R8 was required to promote endosomal escape, or that the R8 mechanism of escape is not compatible with the clathrin pathway. In a different cell line (polarised MDCK cells), both CME and macropinocytosis played a role in the internalisation of the same high density R8-functionalised liposomes [115], demonstrating the large influence of cell line on the mechanism of internalisation. In these cells, neither R8 nor L8 liposomes escaped from the endosome.

A number of positively charged polymers, such as PEI and polyamidoamine (PAMAM) dendrimers, are known to exhibit a proton sponge effect where the polymer buffers the $\mathrm{pH}$ of the endosome as it acidifies [116,117]. To maintain a charge balance, chloride ions migrate into the endosome and the increase in ionic concentration causes osmotic swelling of the endosome, which can lead to eventual rupture. Incorporating these proton sponge polymers into shell cross-linked micelles and polymer particles has enabled the endosomal escape of plasmid and proteins from acidified compartments. PLGA-based nanoparticles have also been observed to escape the endosome via a mechanism linked to the acidification of the early endosome. The decrease in $\mathrm{pH}$ causes charge reversal of the particles from negative (at $\mathrm{pH} 7$ ) to positive (at $\mathrm{pH}$ 5) [118], leading to local destabilisation of the endosomal membrane. The incorporation of pore forming peptides and proteins has also been demonstrated to promote endosomal escape. Stier and co-workers have demonstrated that Listeriolysin protein encapsulated within $\mathrm{pH}$-responsive liposomes promotes endosomal escape and improves antigen presentation [119]. Similarly, pore forming peptides can also induce endosomal escape [120].

The structural rearrangement of materials can also be exploited to promote endosomal escape. Most polymersomes are inherently endocytosed and localised within lysosomal compartments [54]. However, polymersomes assembled from the $\mathrm{pH}$ responsive polymer PMPC-PDPA have been shown to induce endosomal escape [54]. In this system, PDPA is uncharged and hydrophobic at $\mathrm{pH} 7$, but becomes protonated at low $\mathrm{pH}$, causing the polymersome to disassemble. This not only releases the cargo trapped in the polymersomes, but the osmotic pressure caused by the increase in free polymer concentration can cause the endosomal compartment to rupture.

\section{Conclusions}


There has been significant progress in the development of engineered colloidal drug carriers over the last 5 to 10 years. In particular, a number of intelligent loading and release mechanisms have demonstrated significant potential in in vitro studies. However, challenges still remain. The most pressing challenge is to evade the body's natural foreign defence mechanisms to allow long blood circulation times. Shape and PEGylation have been demonstrated to significantly improve the blood circulation times, and a number of systems based on PEGylation have progressed to clinical trials. However, the biodistribution of these systems still results in non-specific organ accumulation and the side effects of chemotherapy-based therapies remain severe. Other colloidal systems developed recently, such as polymersomes, LbL capsules and PRINT particles, have had limited studies regarding biodistribution, but significant efforts are underway to address this gap. Most significantly, polyion complexes have recently demonstrated the first clinical efficacy of siRNA in humans. To improve the efficiency of delivery, particles functionalised with surface targeting ligands to specifically target diseased cells have shown very promising results in vitro; however, in vivo results have yet to demonstrate the same level of improvement. As significant efforts are being employed to tackle the challenges outlined in this review, it is anticipated that over the next 5 years will lead to considerable advances in this dynamic research area and continued translation of colloidal delivery systems into the clinic.

\section{Acknowledgements}

This work was supported by the Australian Research Council under the Federation Fellowship, Discovery Project and Postdoctoral Fellowship schemes, and by the National Health and Medical Research Council under the Program Grant 487922. We thank Dr Yan Yan, Dr Hannah Lomas and Marc Riemer for critical reading of the manuscript.

\section{References}

1. Davis ME, Chen Z, Shin DM. Nanoparticle therapeutics: an emerging treatment modality. Nat Rev Drug Discovery 2008;7:771.

2. Dobrovolskaia MA, McNeil SE. Immunological properties of engineered nanomaterials. Nat Nanotechnol 2007;2:469.

3. Stuart MAC, Huck WTS, Genzer J, Muller M, Ober C, Stamm M, Sukhorukov GB, Szleifer I, Tsukruk VV, Urban M, Winnik F, Zauscher S, Luzinov I, Minko S. Emerging applications of stimuli-responsive polymer materials. Nat Mater 2010;9:101.

4. Vallet-Regi M, Balas F, Arcos D. Mesoporous materials for drug delivery. Angew Chem Int Ed 2007;46:7548.

5. Lee LA, Niu ZW, Wang Q. Viruses and virus-like protein assemblies-chemically programmable nanoscale building blocks. Nano Res 2009;2:349. 
6. Immordino ML, Dosio F, Cattel L. Stealth liposomes: review of the basic science, rationale, and clinical applications, existing and potential. Int J Nanomed 2007;1:297.

7. Peer D, Karp JM, Hong S, Farokhzad OC, Margalit R, Langer R. Nanocarriers as an emerging platform for cancer therapy. Nat Nanotechnol 2007;2:751.

8. Drummond DC, Noble CO, Hayes ME, Park JW, Kirpotin DB. Pharmokinetics and in vivo drug release rates in liposomal nanocarrier development. J Pharm Sci 2008;11:4696.

9. Lasic DD. Sterically stabilized vesicles. Angew Chem Int Ed 1994;33:1685.

10. Allen TM, Cullis PR. Drug delivery systems: entering the mainstream. Science 2004;303:1818.

11. van Dongen SFM, de Hoog HPM, Peters RJRW, Nallani M, Nolte RJM, van Hest JCM. Biohybrid polymer capsules. Chem Rev 2009;109:6212.

12. Doshi N, Mitragotri S. Designer biomaterials for nanomedicine. Adv Funct Mater 2009;19:3843.

*13. Geng Y, Dalhaimer P, Cai SS, Tsai R, Tewari M, Minko T, Discher DE. Shape effects of filaments versus spherical particles in flow and drug delivery. Nat Nanotechnol 2007;2:249.

This paper demonstrates that worm-like filamentous micelles have significantly longer blood circulation times than spherical micelles.

14. Kim KT, Meeuwissen SA, Nolte RJM, van Hest JCM. Smart nanocontainers and nanoreactors. Nanoscale 2010;2:844.

15. Du JZ, Reilly RZ. Advances and challenges in smart and functional polymer vesicles. Soft Matter 2009;5:3544.

16. Tong R, Christian DA, Tang L, Cabral H, Baker JR, Kataoka K, Discher DE, Cheng J. Nanopolymeric therapeutics. MRS Bulletin 2009;34:422.

17. Meng F, Zhong Z, Feijen J. Stimuli-responsive polymersomes for programmed drug delivery. Biomacromolecules 2009;10:197.

18. Discher BM, Won YY, Ege DS, Lee JCM, Bates FS, Discher DE, Hammer DA. Polymersomes: tough vesicles made from diblock copolymers. Science 1999;284:1143.

19. Battaglia G, Ryan AJ, Tomas S. Polymeric vesicles permeability: a facile chemical assay. Langmuir 2006;22:4910.

20. Lee JC-M, Santore M, Bates FS, Discher DE. From membranes to melts, rouse to reptation: diffusion in polymersome versus lipid bilayers. Macromolecules 2002;35:323. 
21. Onaca O, Enea R, Hughes DW. Stimuli-responsive polymersomes as nanocarriers for drug and gene delivery. Macromol Biosci 2009;9:129.

22. Panyam J, Labhasetwar V. Biodegradable nanoparticles for drug and gene delivery to cells and tissue. Adv Drug Delivery Rev 2003;55:329.

23. Mishra B, Patel BB, Tiwari S. Colloidal nanocarriers: a review on formulation technology, types and applications towards drug delivery. Nanomedicine 2009;6:9.

24. Nguyen DN, Green JJ, Chan JM, Langer R, Anderson DG. Polymeric materials for gene delivery and DNA vaccination. Adv Mater 2009;21:847.

25. Kakizawa K, Kataoka K. Block copolymer micelles for delivery of genes and other compounds. Adv Drug Delivery Rev 2002;54:203.

26. Elsabahy M, Wazen N, Bayó-Puxan N, Deleavey G, Servant M, Damha MJ, Lerous JC. Delivery of nucleic acids through the controlled disassembly of multifunctional nanocomplexes. Adv Funct Mater 2009;19:3862.

27. Oishi M, Nagasaki Y, Itaka K, Nishiyma N, Kataoka K. Lactosylated poly(ethylene glycol)-siRNA conjugate through acid-labile $\beta$-thiopropionate linkage to construct $\mathrm{pH}$-sensitive polyion complex micelles achieving enhanced gene silencing in hepatoma cells. J Am Chem Soc 2005;127:1624.

**28. Davis ME, Zuckerman JE, Choi, CHJ, Seligson D, Tolcher A, Alabi CA, Yen Y, Heidel JO, Ribas A. Evidence of RNAi in humans from systematically administered siRNA via targeted nanoparticles. Nature 2010;464:1067.

The first report of the successful clinical application of siRNA delivery using a nanoengineered colloidal carrier.

29. Decher G. Fuzzy nanoassemblies: towards layered polymeric multicomposites. Science 1997;277:123.

30. Quinn JF, Johnston APR, Such GK, Zelikin AN, Caruso F. Next generation, sequentially assembled ultrathin films: beyond electrostatics. Chem Soc Rev 2007;36:707.

31. Caruso F, Caruso RA, Möhwald H. Nanoengineering of inorganic and hybrid hollow spheres by colloidal templating. Science 1998;282:1111.

32. Schneider GF, Subr V, Ulbrich K, Decher G. Multifunctional cytotoxic stealth nanoparticles. A model approach with potential for cancer therapy. Nano Lett 2009;9:636.

33. De Koker S, De Geest BG, Cuvelier C, Ferdinande L, Deckers W, Hennink WE, De Smedt S, Mertens N. In vivo cellular uptake, degradation, and biocompatibility of polyelectrolyte microcapsules. Adv Funct Mater 2007;17:3754. 
34. Zelikin AN, Quinn JF, Caruso F. Disulfide cross-linked polymer capsules: en route to biodeconstructible systems. Biomacromolecules 2006;7:27.

35. Kinnane CR, Such GK, Antequera-Garcia G, Yan Y, Dodds SJ, Liz-Marzan LM, Caruso F. Low-fouling poly(N-vinyl pyrrolidone) capsules with engineered degradable properties. Biomacromolecules 2009;10:2839.

36. Wang Y, Angelatos AS, Caruso F. Template synthesis of nanostructured materials via layer-by-layer assembly. Chem Mater 2008;20:848.

37. Gratton SEA, Ropp PA, Pohlhaus PD, Luft C, Maddon VJ, Napier ME, DeSimone JM. The effect of particle design on cellular internalisation pathways. Proc Nat Acad Sci USA 2008;105:11613.

38. Canelas DA, Herlihy KP, DeSimone JM. Top-down particle fabrication: control of size and shape for diagnostic imaging and drug delivery. Wiley Interdiscip Rev Nanomed Nanobiotechnol 2009;1:391.

39. Gratton SEA, Williams SS, Napier ME, Pohlhaus PD, Zhou ZL, Wiles KB, Maynor BW, Shen C, Olafsen T, Samulski ET, Desimone JM. The pursuit of a scalable nanofabrication platform for use in material and life science applications. Acc Chem Res. 2008;41:1685.

40. Gabizon A, Shmeeda H, Barenholtz Y. Pharmacokinetics of pegylated liposomal doxorubicin - review of animal and human studies. Clin Pharmacokinetics 2003;42:419.

41. Tan ML, Choong PFM, Dass CR. Recent developments in liposomes, microparticles and nanoparticles for protein and peptide drug delivery. Peptides, 2010;31:189.

42. Simões S, Moreira JN, Foneseca C, Nügüneş N, Pedroso de Lima MC. On the formulation of $\mathrm{pH}$-sensitive liposomes with long circulation times. Adv Drug Delivery Rev 2004;56:947.

43. Obata Y, Tajima S, Takeoka S. Evaluation of pH-responsive liposomes containing amino acid-based zwitterionic lipids for improving intracellular drug delivery in vitro and in vivo. J Controlled Release 2010;142:267.

44. Koizumi F, Kitagawa M, Negishi T, Onda T, Matsumoto S, Hamaguchi T, Matsumura Y. Novel SN-38-incorporating polymeric micelles, NK012, eradicate vascular endothelial growth factor-secreting bulky tumors. Cancer Res 2006;66:10048.

45. Hamaguchi T, Matsumura Y, Suzuki M, Shimizu K, Goda R, Nakamura I, Nakatomi I, Yokoyama M, Kataoka K, Kakizoe T. NK105, a paclitaxel-incorporating micellar nanoparticle formulation, can extend in vivo antitumour activity and reduce the neurotoxicity of paclitaxel. Br J Cancer 2005;92:1240. 
46. Yokoyama M, Sugiyama T, Okano T, Sakurai Y, Naito M, Kataoka K. Analysis of micelle formation of an adriamycin-conjugated poly(ethylene glycol)-poly(aspartic acid) block copolymer by gel permeation chromatography. Pharm Res 1993;10:895.

47. Yokoyama M, Okano T, Sakurai Y, Kataoka K. Improved synthesis of adriamycin-conjugated poly(ethylene glycol)-poly(aspartic acid) block copolymer and formation of unimodal micellar structure with controlled amount of physically entrapped adriamycin. J Controlled Release 1994;32:269.

48. Matsumura Y, Hamaguchi T, Ura T, Muro K, Yamada Y, Shimada Y, Shirao K, Okusaka T, Ueno H, Ikeda M, Watanabe N. Phase I clinical trial and pharmacokinetic evaluation of NK911, micelle-encapsulated doxorubicin. Br J Cancer 2004;91:1775.

49. Yoo HS, Park TG. Biodegradable polymeric micelles composed of doxorubicin conjugated PLGA-PEG block copolymer. J Controlled Release 2001;70:63.

50. Bae Y, Fukushima S, Harada A, Kataoka K. Design of environment-sensitive supramolecular assemblies for intracellular drug delivery: polymeric micelles that are responsive to intracellular pH change. Angew Chem Int Ed 2003;42:4640.

51. Bae Y, Nishiyama N, Fukushima S, Koyama H, Matsumura Y, Kataoka K. Preparation and biological characterization of polymeric micelle drug carriers with intracellular $\mathrm{pH}$-triggered drug release property: tumor permeability, controlled subcellular drug distribution, and enhanced in vivo antitumor efficacy. Bioconjug Chem 2005;16:122.

52. Photos PJ, Bacakova L, Discher B, Bates FS, Discher DE. Polymer vesicles in vivo: correlations with PEG molecular weight. J Controlled Release 2003;90:323.

53. Ahmed F, Pakunlu RI, Srinivas G, Brannan A, Bates F, Klein ML, Minko T, Discher DE. Shrinkage of a rapidly growing tumor by drug-loaded polymersomes: pH-triggered release through copolymer degradation. Mol Pharm 2006;3:340.

*54. Lomas H, Canton I, MacNeil S, Du J, Armes SP, Ryan AJ, Lewis AL, Battaglia G. Biomimetic $\mathrm{pH}$-sensitive polymersomes for efficient DNA encapsulation and delivery. Adv Mater 2007;19:4238.

This article demonstrates the assembly of a $\mathrm{pH}$-responsive polymersome that escapes the lysosomal compartment and successfully transfects the cell.

55. Massignani M, LoPresti C, Blanazs A, Madsen J, Armes SP, Lewis AL, Battaglia G. Controlling cellular uptake by surface chemistry, size and surface topology at the nanoscale. Small 2009;5:2424.

56. Little SR; Lynn DM; Purmam SV; Langer R. The effect of particle design on cellular internalization pathways. J Controlled Release 2005;107:449.

*57. Cohen JA, Beaudette TT, Cohen JL, Broaders KE, Dachelder EM, Fréchet JM. Acteal-modified dextran microparticles with controlled degradation kinetics and 
surface functionality for gene delivery in phagocytic and non-phagocytic cells. Adv Mater 2010;in press.

The synthesis of dextran-based microparticles capable of tailored degradation and specific release of DNA, for potential gene therapy applications, is demonstrated.

58. Yan M, Du J, Gu Z, Liang M, Hu Y, Zhang W, Priceman S, Wu L, Zhou H, Liu Z, Seguara T, Tang Y, Lu Y. A novel intracellular protein delivery platform based on single-protein nanocapsules. Nat Nanotechnol 2010;5:48.

59. Harada-Shiba M, Yamauchi K, Harada A, Takamisawa I, Shimokado K, Kataoka $\mathrm{K}$. Polyion complex micelles as vectors in gene therapy - pharmacokinetics and in vivo gene transfer. Gene Ther 2002;9:407.

60. Miyata K, Kakizawa Y, Nishiyma N, Harada A, Yamasaki Y, Koyama H, Kataoka K. Block catiomer polyplexes with regulated densities of charge and disulfide cross-linking directed to enhance gene expression. J Am Chem Soc 2004;126:2355.

61. Matsumoto S, Christie RJ, Nishiyama N, Miyata K, Ishii A, Oba M, Koyama H, Yamasahi Y, Kataoka K. Environment-responsive block copolymer micelle with a disulfide cross-linked core for enhanced siRNA delivery. Biomacromolecules 2009;10:119.

62. Davis ME. The first targeted delivery of siRNA in humans via a self-assembling cyclodextrin polymer-based nanoparticle: from concept to clinic. Mol Pharm 2009;6:659.

63. Kelly JY, DeSimone JM. Shape-specific, monodisperse nano-molding of protein particles. J. Am. Chem. Soc. 2008;130:5438.

64. Zelikin AN, Becker AL, Johnston APR, Wark KL, Turatti F, Caruso F. A general approach for DNA encapsulation in degradable polymer microcapsules. ACS Nano 2007;1:63.

65. Kreft O, Georgieva R, Bäumler H, Steup M, Müller-Röber B, Sukhorukov GB, Möhwald H. Red blood cell templated polyelectrolyte capsules: a novel vehicle for the stable encapsulation of DNA and proteins. Macromol Rapid Commun 2006;27:435.

66. De Cock LJ, De Koker S, De Geest BG, Grooten J, Vervaet C, Remon JP, Sukhorukov GB, Antipina MN. Polymeric multilayer capsules in drug delivery. Angew Chem Int Ed 2010;49:in press.

67. Radt B, Smith T, Caruso F. Optically addressable nanostructured capsules for controlled delivery. Adv Mater 2004;16:2184.

68. Sukhishvilli SA. Responsive polymer films and capsules via layer-by-layer assembly. Curr Opin Colloid Interface Sci 2005;10:37. 
69. Johnston APR, Lee L, Wang Y, Caruso F. Controlled degradation of DNA capsules with engineered restriction-enzyme cut sights. Small 2009;5:1418.

70. De Geest BG, Sander NN, Sukhorukov GB, Demeester J, De Smedt SC. Release mechanisms for polyelectrolyte capsules. Chem Soc Rev 2007;36:636.

71. Sexton A, Whitney PG, Chong SF, Zelikin AN, Johnston APR, De Rose R, Brooks AG, Caruso F, Kent SJ. A protective vaccine delivery system for in vivo $\mathrm{T}$ cell stimulation using nanoengineered polymer hydrogel capsules. ACS Nano 2009;3:3391.

72. De Koker S, De Geest BG, Singh SK, DeRijke R, Naessens T, Van Kooyk K, Demeester J, De Smedt SC, Grooten J. Polyelectrolyte microcapsules as antigen delivery vehicles towards dendritic cells: uptake, processing and cross-presentation of encapsulated antigens. Angew Chem Int Ed 2009;48:8485.

73. Ochs CJ, Such GK, Yan Y, van Koeverden MP, Caruso F. Biodegradable click capsules with engineered drug-loaded multilayers. ACS Nano 2010;4:1653.

74. Sivakumar S, Bansal V, Cortez C, Chong SF, Zelikin AN, Caruso F. Degradable, surfactant-free, monodisperse polymer-encapsulated emulsions as anticancer drug carriers. Adv Mater 2009;21:1820.

75. Yan Y, Johnston APR, Dodds SJ, Kamphuis MMJ, Ferguson C, Parton RG, Nice EC, Heath JK, Caruso F. Uptake and intracellular fate of disulfide-bonded polymer hydrogel capsules for doxorubicin delivery to colorectal cancer cells. ACS Nano 2010;4:2928.

76. Becker AL, Johnston APR, Caruso F. Layer-by-layer assembled capsules and films for therapeutic delivery. Small 2010:in press.

77. Owens DE III, Peppas NA. Opsonization, biodistribution, and pharmacokinetics of polymeric nanoparticles. Int J Pharm 2006;307:93.

78. Bae Y, Kataoka K. Intelligent polymeric micelles from functional poly(ethylene glycol)-poly(amino acid) block copolymers. Adv Drug Delivery Rev 2009;61:768.

79. Wisse E, Braet F, Luo D, DeZanger R, Jans D, Crabbe E, Vermoesen A. Structure and function of sinusoidal lining cells in the liver. Toxicol Pathol 1996;24:100.

80. Liu D, Mori A, Huang L. Role of liposome size and RES blockade in controlling biodistribution and tumor uptake of GM1-containing liposomes. Biochim. Biophys. Acta 1992;1104:95.

81. Fang C, Shi B, Pei YY, Hong MH, Wu J, Chen HZ. In vivo tumor targeting of tumor necrosis factor-alpha-loaded stealth nanoparticles: effect of MePEG molecular weight and particle size. Eur J Pharm Sci 2006;27:27. 
82. Champion JA, Mitragotri S. Role of target geometry in phagocytosis. Proc Nat Acad Sci USA 2006;103:4930.

83. Doshi N, Mitragotri S. Macrophages recognise size and shape of their targets. PLoS One 2010;5:e10051.

84. Christian DA, Cai SS, Garbuzenko OB, Harada T, Zajac AL, Minko T, Discher DE. Flexible filaments for in vivo imaging and delivery: persistent circulation of filomicelles opens the dosage window for sustained tumor shrinkage. Mol Pharm 2009;6:1343.

85. Gratton SEA, PohhauS PD, Lee J, Guo I, Cho MJ, DeSimone JM. Nanofabricated particles for engineered drug therapies: a preliminary biodistribution study of PRINT (TM) nanoparticles. J Controlled Release 2007;121:10.

86. Yamamoto Y, Nagasaki Y, Kato Y, Sugiyama Y, Kataoka K. Long-circulating poly(ethylene glycol)-poly(D,L-lactide) block copolymer micelles with modulated surface charge. J Controlled Release 2001;77:27.

87. Furumoto K, Nagayama S, Ogawara K, Takakura Y, Hashida M, Higaki K, Kimura T. Hepatic uptake of negatively charged particles in rats: possible involvement of serum proteins in recognition by scavenger receptor. J Controlled Release 2004;97:133.

88. Christian DA, Garbuzenko OB, Minko T, Discher DE. Polymer vesicles with a red cell-like surface charge: microvascular imaging and in vivo tracking with nearinfrared fluorescence. Macromol Rapid Commun 2010;31:135.

89. Aggarwal P, Hall JB, McLeland CB, Dobrovolskaia MA, McNeil SE. Nanoparticle interaction with plasma proteins as it relates to particle biodistribution, biocompatibility and therapeutic efficacy. Adv Drug Delivery Rev 2009;61:428.

90. Gref R, Minamitake Y, Peracchia MT, Trubetskoy V, Torchilin V, Langer R. Biodegradable long-circulating polymeric nanospheres. Science 1994;263:1600.

91. Papahadjopoulos D, Allen T, Gabizon A, Mayhew E, Matthay K, Huang SK, Lee KD, Woodle MC, Lasic DD, Redemann C, Martin FJ. Sterically stabilized liposomes: improvements in pharmacokinetics and anti-tumor therapeutic efficacy. Proc Nat Acad Sci USA 1991;88:11460.

92. Matsumura Y, Gotoh M, Muro K, Yamada Y, Shirao K, Shimada Y, Okuwa M, Matsumoto S, Miyata Y, Ohkura H, Chin K, Baba S, Yamao T, Kannami A, Takamatsu Y, Ito K, Takahashi K. Phase I and pharmacokinetic study of MCC-465, a doxorubicin (DXR) encapsulated in PEG immunoliposome, in patients with metastatic stomach cancer. Ann Oncol 2004;15:517.

93. Andresen TL, Jensen SS, Jorgensen K. Advanced strategies in liposomal cancer therapy: problems and prospects of active and tumor specific drug release. Prog Lipid Res 2005;44:68. 
94. Osada K, Christie RJ, Kataoka K. Polymeric micelles from poly(ethylene glycol)poly(amino acid) block copolymer for drug and gene delivery. J Royal Soc Interface 2009;6:S325.

95. Yokoyama M, Okano T, Sakurai Y, Fukushima S, Okamoto K, Kataoka K. Selective delivery of adriamycin to a solid tumor using a polymeric micelle carrier system. J Drug Target 1999;7:171.

96. Torchilin VP. Micellar nanocarriers: pharmaceutical perspectives. Pharm Res 2007;24:1

97. Nishiyama N, Kataoka K. Current state, achievements, and future prospects of polymeric micelles as nanocarriers for drug and gene delivery. Pharmacol Therapeut 2006;112:630.

98. Hobbs SK, Monsky WL, Yuan F, Roberts WG, Griffith L, Torchilin VP, Jain RK. Regulation of transport pathways in tumor vessels: role of tumor type and microenvironment. Proc Nat Acad Sci USA 1998;95:4607.

99. Matsumura K. Poly(amino acid) micelle nanocarriers in preclinical and clinical studies. Adv Drug Delivery Rev 2008;60:899.

100. Low PS, Walter AH, Doorneweerd DD. Discovery and development of folicacid-based receptor targeting for imaging and therapy of cancer and inflammatory diseases. Acc Chem Res 2008;41:120.

101. Lee SM, Chen H, O’Halloran TV, Nguyen ST. “Clickable” polymer-caged nanobins as a modular drug delivery platform. J Am Chem Soc 2009;131:9311.

102. Kim SH, Jeong JH, Chun KW, Park TG. Target-specific cellular uptake of PLGA nanoparticles coated with poly(L-lysine)-poly(ethylene glycol)-folate conjugate. Langmuir 2005;21:8852.

103. Bae Y, Nishiyama N, Kataoka K. In vivo antitumor activity of the folateconjugated $\mathrm{pH}$-Sensitive polymeric micelle selectively releasing adriamycin in the intracellular acidic compartments. Bioconjug Chem 2007;18:1131.

*104. Kamphuis MMJ, Johnston APR, Such GK, Dam HH, Evans RA, Scott AM, Nice EC, Heath JK, Caruso F. Targeting of cancer cells using click-functionalized polymer capsules. J Am Chem Soc. Submitted.

This paper demonstrates the antibody functionalisation of LbL capsules using click chemistry. Specific targeting to cancer cells was observed even when the target cell population was less than $0.1 \%$ of the total cell population.

105. Kirpotin DB, Drummond DC, Shao Y, Shalaby MR, Hong K, Nielsen UB, Marks JD, Benz CC, Park JW. Antibody targeting of long-circulating lipidic nanoparticles does not increase tumor localization but does increase internalization in animal models. Cancer Res 2006;66:6732. 
106. Farokhzad OC, Cheng J, Teply BA, Sherifi I, Jon S, Kantoff PW, Richie JP, Langer R. Targeted nanoparticle-aptamer bioconjugates for cancer chemotherapy in vivo. Proc Nat Acad Sci USA 2006;103:6315.

*107. Hillaireau H, Couvreur P. Nanocarriers' entry into the cell: relevance to drug delivery. Cell Mol Life Sci 2009;66:2873.

A comprehensive review of the internalisation mechanisms of cells and how they relate to colloidal drug carriers.

108. Khalil IA, Kogure K, Akita H, Harashima H. Uptake pathways and subsequent intracellular trafficking in nonviral gene delivery. Pharmacol Rev 2006;58:32.

109. Mercer J, Helenius A. Virus entry by macropinocytosis. Nat Cell Biol 2009;11:510.

110. Rejman J, Oberle V, Zuhorn IS, Hoekstra D. Size-dependent internalization of particles via the pathways of clathrin- and caveolae-mediated endocytosis. Biochem J 2004;377:159.

111. Harush-Frenkel O, Debotton N, Benitam S, Altschuler Y. Targeting of nanoparticles to the clathrin-mediated endocytic pathway. Biochem Biophys Res Commun 2007;353:26.

112. Dausend J, Musyanovych A, Dass M, Walther P, Schrezenmeier H, Landfester $\mathrm{K}$, Mailänder V. Uptake mechanism of oppositely charged fluorescent nanoparticles in HeLa cells. Macromol Biosci 2008;8:1135.

113. El-Sayed A, Khalil IA, Kogure K, Futaki S, Harashima H. Octaarginine- and octalysine-modified nanoparticles have different modes of endosomal escape. J Biol Chem 2008;283:23405.

114. Khalil IA, Kogure K, Futaki S, Harashima H. High density of octaarginine stimulates macropinocytosis leading to efficient intracellular trafficking for gene expression. J Biol Chem 2006;281:3544.

115. Fujiwara T, Akita H, Harashima H. Intracellular fate of octaarginine-modified liposomes in polarized MDCK cells. Int J Pharm 2010;386:122.

116. Pack DW, Hoffman AS, Pun S, Stayton PS. Design and development of polymers for gene delivery. Nat Rev Drug Discovery 2005;4:581.

117. Sonawane ND. Chloride accumulation and swelling in endosomes enhances DNA transfer by polyamine - DNA polyplexes. J Biol Chem 2003;278:44826.

118. Panyam J, Zhou WZ, Prabha S, Sahoo SK, Labhasetwar V. Rapid endolysosomal escape of poly(DL-lactide-co- glycolide) nanoparticles: implications for drug and gene delivery. FASEB J 2002;16:1217. 
119. Stier EM, Mandal M, Lee KD. Differential cytosolic delivery and presentation of antigen by listeriolysin O-liposomes to macrophages and dendritic cells. Mol. Pharmaceutics. 2005;2:74.

120. Turk MJ, Reddy JA, Chmielewski JA, Low PS. Characterization of a novel pHsensitive peptide that enhances drug release from folate-targeted liposomes at endosomal pHs. Biochim. Biophys. Acta, Biomembr. 2002;1559:56 


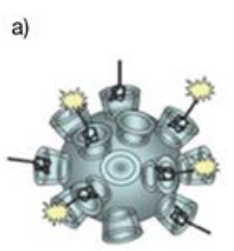

b)

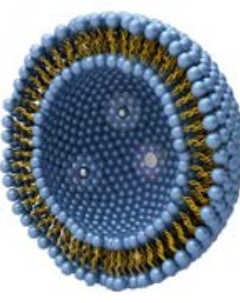

c)

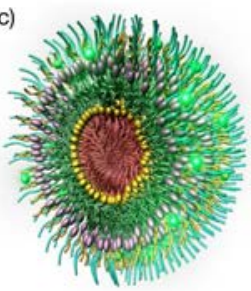

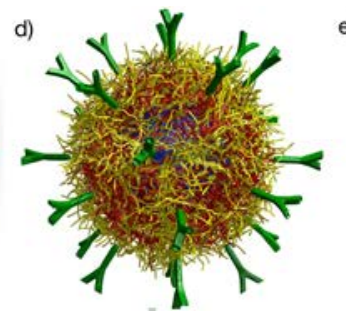

Figure 1. Examples of colloidal carriers: a) Polymer particles (modified with cyclodextran); b) Liposomes/polymersomes; c) Polymer micelles; d) LbL capsules (functionalised with antibodies on their surface); e) PRINT particles. b) Taken from http://techtransfer.universityofcalifornia.edu/NCD/19354.html. http://techtransfer.universityofcalifornia.edu/NCD/19775.html. http://www.desimone-group.chem.unc.edu/research/print.

c) Taken from

e) Taken from
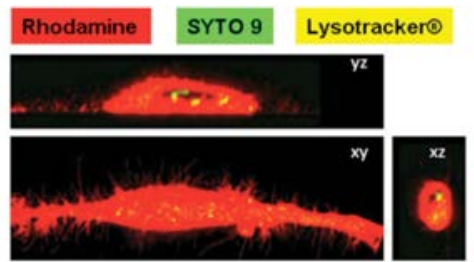

pH sensitive polymersomes

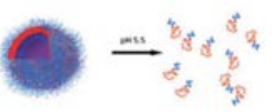

b)

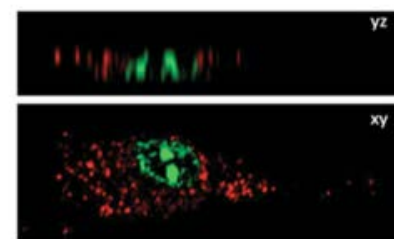

Non-pH sensitive polymersomes.
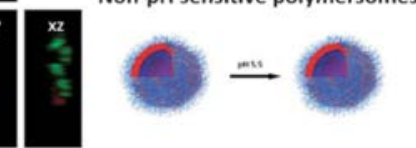

Figure 2. In vitro disassembly of $\mathrm{pH}$-responsive polymersomes. Polymer labelled with rhodamine (red), DNA in the nucleus labelled with Syto 9 (green), and lysosomes labelled with lysotracker (yellow). a) pH-responsive polymersomes showed distribution of the polymer throughout the cell, indicating disassembly of the polymersome structure and release into the cytoplasm. b) Non-responsive polymersomes remained in distinct compartments within the cell. Taken from Ref. [55], with permission. 


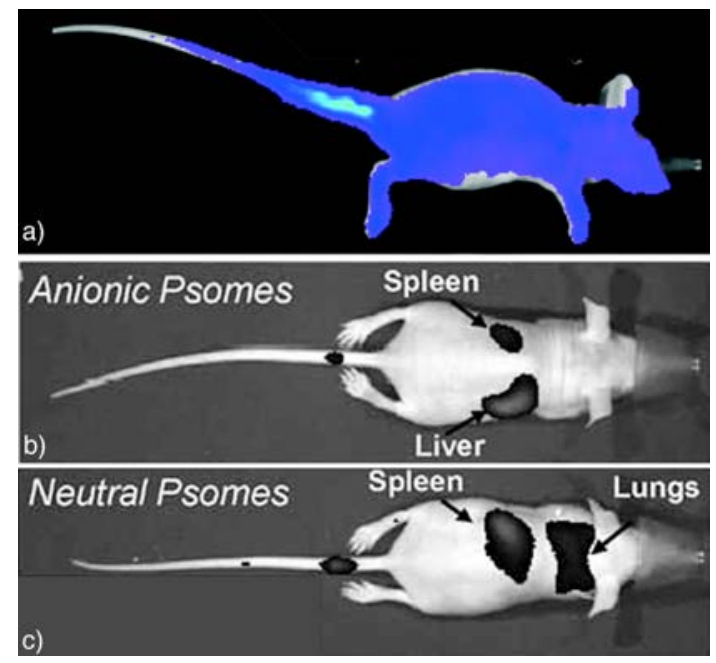

Figure 3. Biodistribution of filomicelles and polymersomes in mice. a) Filomicelles show distribution throughout the mouse after $4 \mathrm{~h}$, compared to accumulation in the b) liver and spleen for anionic polymersomes and c) lungs and spleen for neutral polymersomes. a) Taken from Ref. [84], with permission. b, c) Taken from Ref. [88], with permission.

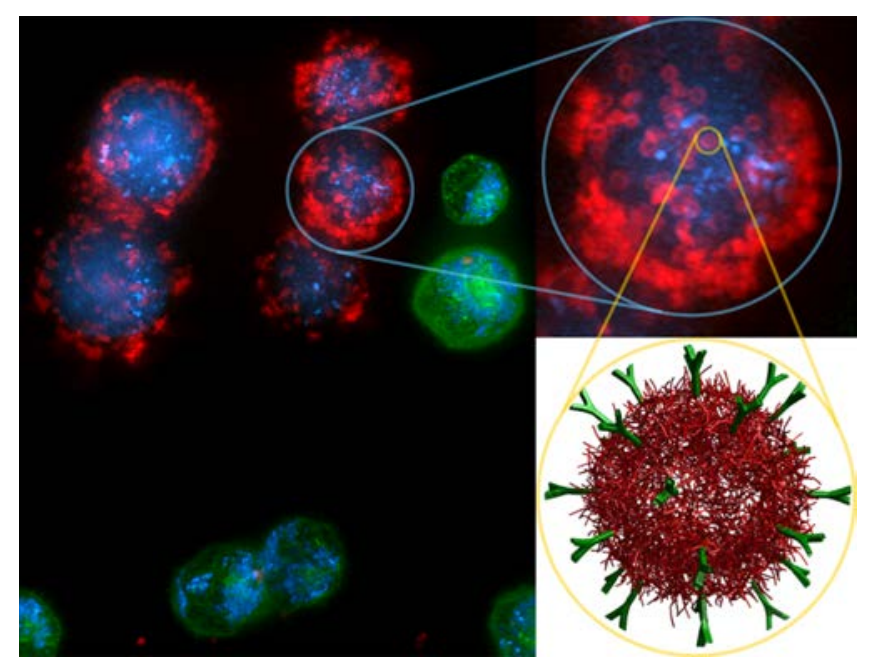

Figure 4. Targeting antibody-functionalised LbL-assembled capsules to cancer cells. Cells expressing the huA33 antigen (blue) and cells that do not express the huA33 antigen (green) were incubated with capsules functionalised with the huA33 antibody. Taken from Ref. [104], with permission. 


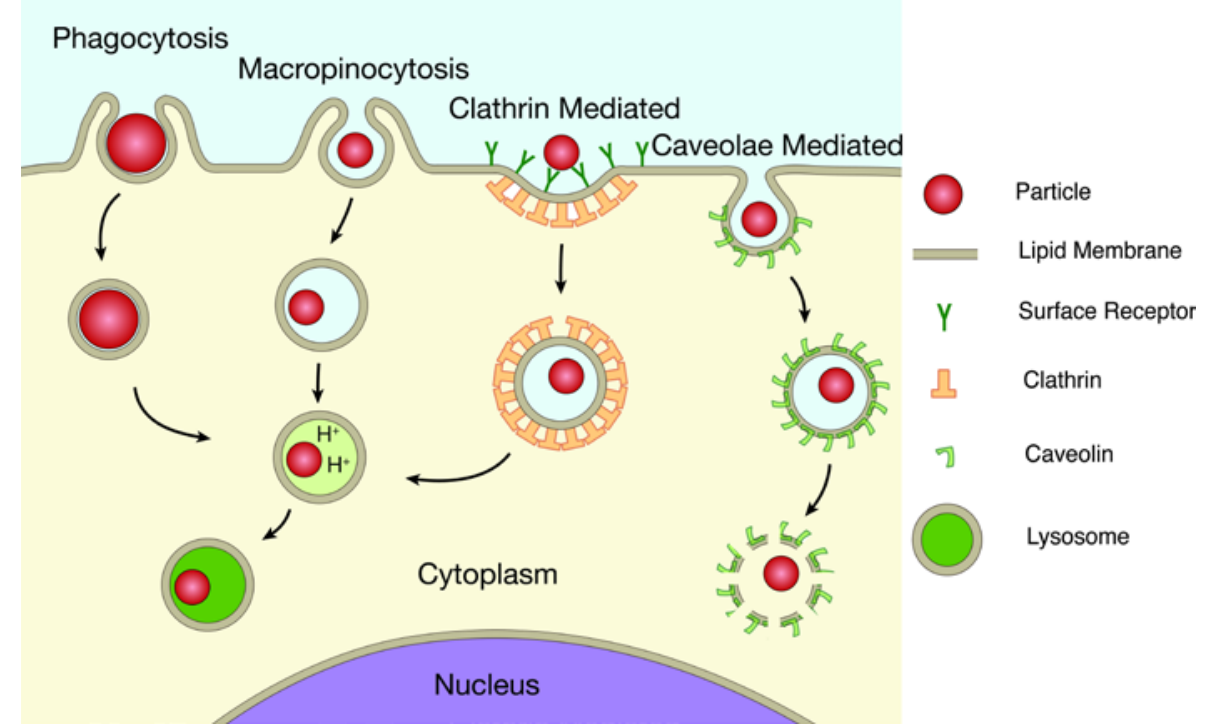

Figure 5. Schematic of particle internalisation into cells. Phagocytosis, macropinocytosis and clathrin-mediated endocytosis generally lead to acidification of the endosomal compartment followed by fusion with the lysosome. For maximum therapeutic effect, the particles need to be engineered to escape from this lysosomal pathway. In contrast caveolae-mediated endocytosis does not enter the lysosomal pathway. 
Table of Contents graphic

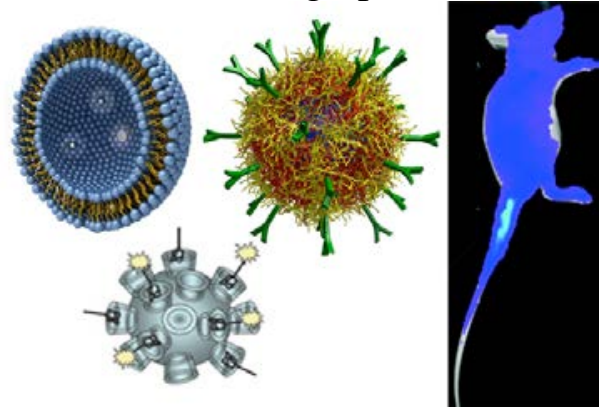

